\title{
Development and understanding of caloric responses; an overview of the first hundred years
}

\begin{abstract}
In 1906 Robert Barany published his original research on the caloric test and his convection theory to explain the direction of nystagmus. Subsequent publications by others suggested different explanations, including the effect of temperature on the vestibular nerves, pressure changes in the ampulla related to temperature expansion, but also the possibility of otolith modulation of the response. Technical developments have allowed quantitative measurement of the caloric response using electronystagmography; caloric assessment consists of measuring the slow phase velocity of nystagmus and uses the JongkeesPhillipszoon equation (difference over sum) to detect pathology. The caloric test has become an entrenched assessment in the evaluation of patients with vestibular complaints. Barany's convection theory was accepted as the explanation for the fact that with the lateral semicircular canal at right angles to horizontal (30degrees head up) the response to caloric irrigation was greater with the patient supine (face up) than prone (face down). The convection theory was questioned when caloric responses in the appropriate direction were documented during space flight. It seems that there are many factors affecting the underlying convection caloric response that has been advanced for the last century.
\end{abstract}

Keywords: barany, calorics, semicircular canals, otoliths
Volume 3 Issue 2 - 2015

Longridge NS,' Mallinson AI,' Pothier DD²

'Neuro-otology unit Vancouver General Hospital, Division of Otolaryngology Department of Surgery, Faculty of Medicine, University of British, USA

${ }^{2}$ Department of Otolaryngology- head and neck surgery, Faculty of Medicine, University of Toronto, Canada

Correspondence: Neuro-otology unit Vancouver General Hospital, Division of Otolaryngology Department of Surgery, Faculty of Medicine, University of British, USA,

Email nslongridge@hotmail.com

Received: April 07, 20I5 | Published: August 22, 2015

\section{Introduction}

In 1914 Robert Barany was awarded the Nobel Prize in Medicine and Physiology for publishing his discovery of the caloric response and his convection explanation for its occurrence in $1906 .{ }^{1}$ At the time of the award he was being held as a prisoner of war by the Russian authorities and was working in a hospital in central Russia treating war wounded. He accepted the prize in Stockholm in 1916 after release from prison, thanks to the efforts of the Red Cross and the royal families of Sweden and Russia. The prize came with a substantial financial award, which Barany, as a good Austrian, invested in Austrian war bonds and lost what would have been an income for life. Faced with jealousy in Vienna, where he had accomplished the work resulting in the award, he took the opportunity to accept the professorship of otolaryngology at the University of Uppsala, Sweden, where he worked for the rest of his life. His account of the recognition of caloric-induced dizziness is a tribute to him as a physician. As a result of listening to his patient, he was able to recognize previously unrecognized information and ascribe significance to it.

In his address during his acceptance of the award in $1916^{2}$ he described a patient who, while having their ear syringed stated, "Doctor, you are making me dizzy. I use warmer water than this and I do not get dizzy." Barany requested his nurse to bring warmer water to repeat the procedure and when she returned he stated that the water was not warm enough and sent her out for hotter water. (Barany had a reputation of being irascible and it is likely that the instructions to the nurse about the temperature of the water were somewhat aggressive). She returned with very hot water, which Barany used, and the patient stated, "Doctor, you are using warmer water than I use and I am dizzy again." It was known that nystagmus could occur with ear syringing and that the direction was always the same, (fast phase away from the syringed ear). Barany followed 20 patients, finding consistently that warm water induced nystagmus with the fast phase of nystagmus towards the irrigated side; the opposite was true for cold water. The mnemonic COWS; - "cold opposite; warm same" - is now memorized by medical students and residents.
Why was Barany flushing ears in this way? The reason is that at that time, the management of chronic ear discharge related to suppurative otitis media, or cholesteatoma was syringing to reduce the odour. Surgical intervention was undertaken only as an emergency procedure in extreme situations. At the turn of the last century anesthesia was still new and was hazardous and consisted of dripping chloroform on a mask over the mouth and nose. Magnification such as a microscope and even loupes was not available. Technical assistance such as suction was less effective, and lighting was limited (as the electric light bulb had only been invented two decades previously and the tungsten filament as a bright light source did not exist until 1910). In summary, surgical intervention was undertaken only as an extreme procedure. Illumination consisted of either daylight or a feeble electric light bulb and head mirror. The technical equipment for doing the bone cutting was a mallet and gouge (hammer and chisel). This combination of poor lighting, no magnification and limited bone removal equipment placed the facial nerve at risk. In addition, clearing the disease was by no means guaranteed, so that a patient could be faced with a combination of facial paralysis and continued disease. As a result, management or ear disease was conservative; frequent syringing with water to flush away the smell. Syringing would be undertaken by the patient up to several times a day, with occasional follow up and syringing by the otolaryngologist.

It was during such a follow up on one of his patients that Bárány made his observations about dizziness related to the temperature effects of water. After noticing that hot water syringing consistently produced nystagmus in the opposite direction to that of cold water syringing, he worked out the convection theory based on how a fire at his home was used to heat a tank of water. Heating the water in a lower tank by the fire caused the hot water to rise up a pipe to a higher tank, and water from the upper tank flowed down another pipe to be heated by the fire. As a boy he had noted the upper tank to be too hot to touch and the lower tank by the fire was cool.

To confirm his convection theory Bárány syringed a patient face down and the direction of nystagmus was reversed, supporting his 
"hot fluid rises" convection theory as the explanation for the caloric response. As a result of this new understanding, caloric testing was developed as an assessment technique of the inner ear, as a clinical quantitative measurement of semicircular canal response. In the early years after its introduction to assess the inner ear, comparison of the duration of nystagmus after irrigating each side was the most commonly used parameter that could be measured, initially with fixation and later with fixation removed (Frenzel's lenses). Frequency of nystagmus could also be estimated as an alternative measure. Although Barany's original convection theory is still the favoured theory for the explanation of why caloric responses occur, other explanations were suggested in the years following his publication of this explanation. A review of these is offered by Jongkees, ${ }^{3}$ suggesting various theories for the caloric response in the German literature.

These theories included the following:

i. Bartels ${ }^{4}$ suggested the effect was a direct effect of heat on the nerves, heat being a stimulant and cold a depressant.

ii. Kobrak ${ }^{5}$ suggested a vascular effect; cold causing vasoconstriction peripherally with consequent central vasodilatation resulting in endolymph flow which deflected the cupula.

iii. Borries ${ }^{6}$ suggested that the caloric reaction was a response of the whole labyrinth, especially the otolith.

iv. Brunner et al., ${ }^{7}$ thought that caloric nystagmus was not due to a peripheral response but was of central origin.

v. Jongkees ${ }^{3}$ adapted Van Caneghem's ${ }^{8}$ pressure concept to the semicircular canals as the explanation of the caloric response.

In 1942 Fitzgerald \& Hall pike ${ }^{9}$ described the bithermal caloric test. $^{9}$

The maximum caloric response is obtained with the patient lying $30^{\circ}$ head up from the horizontal to make the lateral semicircular canal vertical, and hence maximize the convective effect in the canal. Behrman. ${ }^{10}$ had published a paper describing doing the caloric test with the patient's head at angles other than $30^{\circ}$ head up. By doing the caloric test with the patient's head at various angles he found to his surprise that performing calorics with the patient at an angle where the lateral semicircular canal was at right angles to vertical (i.e. where the convection theory dictated that no response should occur) that nystagmus, though of reduced magnitude, did occur. The null point, where no response or reversal of response began to occur was not at $90^{\circ}$ but was at $100^{\circ} ; 10^{\circ}$ further than the expected point. This conundrum was confirmed by McNally ${ }^{11}$ and Jongkees. ${ }^{12}$ Cawthorne $\& \mathrm{Cobb}^{13}$ showed that caloric irrigation was an effective mechanism of stimulating the labyrinth, as the temporal bone was heated effectively by water of the magnitude given in caloric irrigations.

Jongkees' work regarding the history of caloric theory and also his recognition of the $100^{\circ}$ null point, were forgotten, as many investigators (e.g. Henriksson, ${ }^{14}$ Aschan ${ }^{15}$ and, Stahle ${ }^{16}$ described ENG and outlined the assessment parameters which are still in use today. This process took about 15 years with discussions about whether duration, frequency or slow phase velocity was the most reliable and eventually after a great deal of scientific debate it was recognized that slow phase velocity was the most reliable clinical measure of caloric function. ${ }^{17}$ Jongkees ${ }^{18}$ major and persisting contribution was his eponymous formula, and description of the "sum over difference" calculation for hot and cold calorics, representing the threshold of abnormal (i.e. two standard deviations from the mean). This formula is still used today in vestibular assessment and is now being used in VEMP assessment. ${ }^{19}$ This is Jongkees' greatest existing contribution.
Unfortunately in any meta-analysis of caloric studies, his earlier work in 1948 (addressing the state of the art on caloric response) would be lost because pre ENG opinion would be excluded.

In 1963 Coats \& Smith ${ }^{20}$ repeated Jongkees' experiment, measuring the caloric response and rotating patients through $360^{\circ}$ twice, doing an ENG at every $30^{\circ}$ and confirmed a finding of a null point at $100^{\circ}$ as Behrman ${ }^{10}$ had found. Coats used a 40second irrigation (differing from the 30second irrigation accepted as standard), and found a velocity higher in cold water irrigations than in hot water irrigations (with a 30second irrigation, the hot caloric velocity is generally larger than the cold). Barber \& Wright ${ }^{21}$ added a final foible to standard ENG evaluation, pointing out that in the absence of a spontaneous nystagmus, the "sum over difference" formula for hot calorics only could be used, if there was less than a $15 \%$ difference. This "hot caloric screening" was shown to detect pathology in $99 \%$ of cases. The benefit of this is that only approximately $30 \%$ of people needed to undergo a full four caloric test battery; cold calorics were usually unnecessary, reducing test time and patient discomfort. By the 1970s the convection theory had been fully accepted as the explanation for how calorics worked and when caloric irrigation was undertaken on parabolic flights (technically a difficult thing to do, as water calorics could not be used). Calorics were carried out using air, which is a much less reliable heat and cold source). ${ }^{22}$ It was found that nystagmus was abolished during the weightless period. This was regarded as final proof of the convection theory.

As predicted by vestibular scientists, ${ }^{23,24}$ caloric tests undertaken on the first day or two of space flight (using an air stimulus in orbital flight) showed very little caloric response. However several days into the space flight the velocity of caloric response returned to approximately the same magnitude as the pre flight velocities in the astronauts. This led Scherer \& Clark $^{25}$ to repeat Jongkees' ${ }^{12}$ and Coats $\&$ Smith's ${ }^{20}$ work to measure the caloric response with the lateral semicircular canal at various angles to vertical. They confirmed the previously reported null point of $100^{\circ}$. Their concern at this point was to explain why this was not the $90^{\circ}$ that should theoretically be the case. One of the theories put forward as a possibility and then rejected by various scientists was that depending on lateral semicircular canal orientation to gravity, caloric responses are modulated by the otoliths. ${ }^{6,20}$ Coats and Smith list a number of other investigators who suggest that otoliths are a modulating influence on caloric response. The conundrum not explained by altered firing rate due to temperature or expansion of fluid due to temperature is that with face down, caloric responses are less than with face up. ${ }^{20,26}$ The possible ways to explain this are Barany's convection theory or gravity modulated otolithic effects. Luxon has outlined the traditionally held concept that there is a circle of flow of endolymph around the utricle, the semicircular canal and ampulla when the head moves. ${ }^{27}$ However as far back as 1935, it was shown by Dohlman that there is in fact a complete occlusion of the ampulla by the crista and the cupula and that there is "no flow" during caloric stimulation, but only deviation, slight movement of the crista and cupula. ${ }^{28}$ This changes the concept of how the system works; only small amounts of perilymph and endolymph movement need to occur and the acutely sensitive and tuned semicircular canal system has evolved to detect these minimal fluid movements. It also needs to be remembered that when the head is turned fast there is only a slight difference in the amount of fluid movement in the laterally placed ampulla compared to the most medial portion of the semicircular canal. Direction of movement of both is the same as they are on the same side of the head. Flow is a concept assumed for the convection theory of the caloric test, and Dolman's work raises some questions about the theory. 
Chemical constitution of endolymph is very distinct with a high potassium concentration actively maintained. The need for this unique constitution is to have the cochlea and labyrinthine systems independent of the variable blood concentration of these and other ions in order to have function maintained maximally independent, of dietary ingestion of $\mathrm{Na}+$ and $\mathrm{K}+$, for example. The intraendothelial membranous labyrinth offers this protection to the end organs, although the cellular separation of perilymph to endolymph is very thin. This means that when a head turns, the inertia of fluid in the perilymph is a factor in movement of the cupula. It is unknown how friction of fluid movement in the 2 compartments of the semicircular canal affects movement of the crista in the ampulla, particularly if the movement is off direct flow axis and affects at least 2 canals, as most head movements do. Complex calculations have been made with significant assumptions related to endolymph movement alone..$^{23,29}$ To date nobody has addressed the contribution of perilymph movement as a factor in the calculations. It has been shown that there is a caloric flow of fluid in the ampulla but the relevance of this to normal function has to be questioned. ${ }^{30}$ Apart from convection, alternative theories for why caloric responses should occur are: an expansion effect due to heat and cold on the lateral semicircular canal:;0,31 a change in firing rate of neurons due to heat and cold in the lateral semicircular canal. ${ }^{32}$ The other alternative is otolithic modulation due to the position of the macula system with respect to the lateral semicircular canal and its relationship to gravity. ${ }^{6,20}$ The effect of friction and differential effects of relative movement of endolymph and perilymph when a movement is off axis relative to the semicircular canal is not as yet understood.

The traditional assessment of the semicircular canal system is the well known caloric test. However the semicircular canal system's function is to detect rapid head movements of brief duration, often less than a second. The prolonged stimulation (30seconds) necessary for a caloric response is completely a physiological. Despite this, the caloric test has stood the test of time, (although not the test of physiological explanation). This is because until very recently it was the only test where pathology could be lateralized; the side being tested is known and any measured response is due to stimulation of the tested side. The head thrust test is a more physiological method of measuring function by evaluating the vestibulo-ocular reflex in real time. The standard head thrust test is done with the head held in the routine upright position, which means that the lateral semicircular canal is $30^{\circ}$ up. The posterior and superior canal of the opposite inner ear are directed in such a way that a left head thrust stimulates the posterior and superior canal vectors on the right. This may be one of the reasons that the head thrust test, although positive at first after an insult, becomes negative in the chronic patient. Other possibilities are direct physical recovery of function from the insult (healing) and brainstem readjustment to balance the system. Mohammed Hamid ${ }^{32}$ states that a $50 \%$ reduction in caloric response is necessary before the head thrust becomes abnormal. Be that as it may, that heat and cold change the firing rate on expansion of end organ perilymph and endolymph deviating the cupula is an explanation for the caloric response but it is not the whole story based on the fact that neither of these explains the changed in direction of nystagmus by turning the patient over and doing the test in reverse manner. It is known that with head down the responses for both hot and cold calorics are less than with head up..$^{20}$ This difference may be explained either by the expansion and contraction due to the effect of temperature on endo and perilymph or by altered neuronal firing rate due to temperature, or both.

All of the above explanations assume a simple vestibular lever effect of cupula movement and completely dismiss any thoughts about the biological nature of the vestibular response. The possibility that stretching of the cupula varies depending on the angle of "flaw"; (i.e. if the movement is not in direct line with a particular semicircular canal). To explain the ability to cope with head movements at different accelerations and decelerations in 3dimensions, vestibulotopia (akin to tonotopia and somatotopia) is almost certainly present. In fish, innervation of the superior and posterior canals differs from mammals as there are 2 nerves to each ampulla, suggesting differential function. ${ }^{33}$ In reptiles the cupula structures are divided by a non sensory strip into two different sensory parts. This is also true in bats and cats.

While Barany's convection theory of semicircular canal function has stood the test of time, the vestibulo-ocular reflex is not an independent subsystem, but image stabilization relies on a variety of inputs. ${ }^{34}$ This was first outlined by Fernandez \& Goldberg ${ }^{35}$ who showed that head translation as sensed by the otoliths is also an important stimulus for compensatory eye movement. It has been shown $^{36}$ that gravitational signals (arising from the otolith organs) and rotational signals (arising from the semicircular canals) interact extensively for accurate estimation of tilt and inertial acceleration. It has also been suggested that conscious perception seems not to play a role in estimating of linear and angular movement parameters during curved-path motion. These estimates of linear (and perhaps angular) components might instead rely on integrated information from canals and otoliths.

This overview of the evolution of the caloric response over the past century suggests that while we have quantified tests of different vestibular structures, and that quite often the test abnormalities are in keeping with a patient's signs and symptoms. Sometimes this is not the case. This reflects our poor understanding of the exceedingly complex caloric/otolithic interaction that has been shown to exist.

\section{Acknowledgments}

None.

\section{Conflicts of interest}

Author declares there are no conflicts of interest.

\section{Funding}

None.

\section{References}

1. Bárány R. Untersuchungen über den vom Vestibularapparat des Ohres reflektorisch ausgelosten rhythmischen Nystagmus und seine Begleiterscheinungen, Monatsschr. F Ohrenh. 1906; 40: 193.

2. Bárány R. Some new methods for functional testing of the vestibular apparatus and the cerebellum. Nobel lecture. 1916.

3. Jongkees LBW. Origin of the caloric reaction of the labyrinth. Arch Otolaryngol. 1948;48(6):645-657.

4. Bartels. in discussion on Bárány and Wittmaack: Funktionelle Prufung des vestibular Apparates, Ber. D. deutsch. otol. Gesellsch. 1911;20(214).

5. Kobrak F. Beitrage zum experimentellen Nystagmus. Physiol Pathu. $1919 ; 10: 214$.

6. Borries GVT .Theorie des kalorischen Nystagmus. Kahlkop. $1925 ; 113: 117$

7. Brunner H, Alexander G, Marburg O. Handbuch des Neurologie des Ohres. Volume III, Urban \& Schwarzenberg, Berlin, Germany. The Laryngoscope. 1926;36(7):544. 
8. Van Caneghem D. Application du Romberg amplifie et de la reaction vestibulaire sonore au diagnostique differentiel entre la tympanosklerose et l'otospongiose, Bull. Soc belge d'otol rhinn laryng. 1946. p. 88.

9. Fitzgerald G, Hallpike SC. Studies in human vestibular function I: Observations on the directional preponderance of caloric nystagmus (nystagmus bereitschaft) resulting from cerebral lesions. Brain. 1942;65(2):115-137.

10. Behrman W. Über Indifferenzlagen und Nystagmusgebiete.: II. Versuche mit horizontal liegenden, nach einseitiger kalorischer Reizung um ihre Längsachse rotierten Personen. Acta Oto-Laryngologica. 1942;30(4):298.

11. McNally WJ, Stuart EA, Jamieson JS, et al.Some experiments with caloric stimulation of the human labyrinth to study the relative values of ampullo-petal and ampullo-fugal endolymphatic flow (Ewald's laws). Trans Amer Acad Ophthal Otolaryng. 1947;52:513.

12. Jongkees LBW. Value of the Caloric Test of the Labyrinth, Utrecht, Netherlands. Arch Otolaryngol. 1948;48(4):402-417.

13. Cawthorne TE, Cobb WA. Temperature changes in the perilymph space in response to caloric stimulation in man. Acta Oto-Laryngol. 1954;44(5-6):580-588.

14. Henriksson NG. Acta Oto-Laryngol Suppl. 1956;125:1.

15. Aschan G, Bergstedt M, Stahle J. Acta Oto-Laryngol Suppl. 1956;129:1.

16. Stahle J. Acta Oto-Laryngol Suppl. 1958;137:1.

17. Robert A, Schindler MD. Manual of electronystagmography. Arch Otolaryngol. 1977;103(12):746.

18. Jongkees LBW, Philipszoon AJ. Acta Oto-Laryngol Suppl. 1964;189:1.

19. Nguyen KD, Welgampola MS, Carey, et al. Test-retest reliability and age-related characteristics of the ocular and cervical vestibular evoked myogenic potential tests. Otol Neurotol . 2010;31(5):793-802.

20. Coats AC, Smith SY. Body Position and the intensity of caloric nystagmus. Acta Otolaryngol. 1967;63(2):515-532.

21. Barber HO, Wright G, Demanuele F. The hot caloric test as a clinical screening device. Arch Otolaryngol. 1971;94(4):335-357.

22. Clarke AH, Scherer H, Gundlach P. Caloric stimulation during short episodes of microgravity. Arch Otorhinolaryngol. 1988;245(3):175-179.
23. Scherer H, Clarke AH. The caloric vestibular reaction in space. Acta Otolaryngol (Stockh). 1985;100(5-6):328-336.

24. Scherer H, Brandt U, Clarke AH, et al.European vestibular experiments on the Spacelab-1 mission: 3. Caloric nystagmus in microgravity. Exp Brain Res. 1986;64(2):255-263.

25. Scherer H Clarke AH. Thermal stimulation of the vestibular labyrinth during orbital flight. Arch Otorhinolaryngol. 1987;244 (3):159-166.

26. Stahle J. Controversies on the caloric response. From Barany's theory to studies in microgravity. Acta Otolaryngol . 1990;109 (3-4):162-167.

27. Luxon L. The anatomy and physiology of the vestibular system, in Vertigo. In: Dix MR \& Hood JD (Eds.). 1984. p. 1-36.

28. Dohlman G. some practical and theoretical points in labyrinth logy (Section of Otology). Proc R Soc Med. 1935;88(2):1371-1380.

29. Melville-Jones G. The functional significance of semicircular canal size. Vestibular System Part 1: Basic Mechanisms. Handbook of Sensory Physiology. 1974; 6(1):171-184.

30. Pau HW, Limberg W. Fluid kinetics of endolymph during rotation. Acta Otolaryngol. 1990;110(1-2):7-10.

31. Wit HP, Spoelstra HAA, Segenhout JM. Barany's theory is right, but incomplete. Acta Otolaryngol . 1990;110(1-2):1-6.

32. Hamid M. More than a $50 \%$ canal paresis is needed for the head impulse test to be positive. Otol Neurotol. 2005;26(2):318-319.

33. Wersall J, Bagger-Sjoback D. Vestibular System Part 1: Basic Mechanisms. In: Kornhuber HH (Ed.), Handbook of sensory physiology. Springer Verlag, New York, USA. 1974. p.123-170.

34. Crane BT, Demer JL. A linear canal otolith interaction model to describe the human vestibulo-ocular reflex. Biol Cybern. 1999;81(2):109-119.

35. Fernandez C, Golberg JM. Physiology of peripheral neurons innervating otolith organs of the squirrel monkey. I. Response to static tilts and to long-duration centrifugal force. J Neurophysiol. 1976;39(5):970-984.

36. Mac Neilage PR, Turner AH, Angelaki DE. Canal-otolith interactions and detection thresholds of linear and angular components during curved-path self-motion. J Neurophysiol. 2014;104(2):765-773. 